\title{
BMJ Open Eliciting willingness-to-pay to prevent hospital medication administration errors in the UK: a contingent valuation survey
}

Sarah R Hill (D) , ${ }^{1}$ Nawaraj Bhattarai, ${ }^{1}$ Clare L Tolley, ${ }^{2}$ Sarah P Slight, ${ }^{2}$ Luke Vale ${ }^{1}$

To cite: Hill SR, Bhattarai N, Tolley CL, et al. Eliciting willingness-to-pay to prevent hospital medication administration errors in the UK: a contingent valuation survey. BMJ Open 2022;12:e053115. doi:10.1136/ bmjopen-2021-053115

- Prepublication history and additional supplemental material for this paper are available online. To view these files, please visit the journal online (http://dx.doi.org/10.1136/ bmjopen-2021-053115).

Received 05 May 2021 Accepted 06 December 2021

Check for updates

(C) Author(s) (or their employer(s)) 2022. Re-use permitted under CC BY-NC. No commercial re-use. See rights and permissions. Published by BMJ.

${ }^{1}$ Health Economics Group, Population Health Sciences Institute, Newcastle University, Newcastle upon Tyne, UK

${ }^{2}$ School of Pharmacy, Newcastle University, Newcastle upon Tyne, UK

Correspondence to

Dr Sarah R Hill;

Sarah.Hill2@newcastle.ac.uk

\section{ABSTRACT}

Medication errors are common in hospitals. These errors can result in adverse drug events (ADEs), which can reduce the health and well-being of patients', and their relatives and caregivers. Interventions have been developed to reduce medication errors, including those that occur at the administration stage.

Objective We aimed to elicit willingness-to-pay (WTP) values to prevent hospital medication administration errors.

Design and setting An online, contingent valuation (CV) survey was conducted, using the random card-sort elicitation method, to elicit WTP to prevent medication errors.

Participants A representative sample of the UK public. Methods Seven medication error scenarios, varying in the potential for harm and the severity of harm, were valued. Scenarios were developed with input from: clinical experts, focus groups with members of the public and piloting. Mean and median WTP values were calculated, excluding protest responses or those that failed a logic test. A two-part model (logit, generalised linear model) regression analysis was conducted to explore predictive characteristics of WTP.

Results Responses were collected from 1001 individuals. The proportion of respondents willing to pay to prevent a medication error increased as the severity of the ADE increased and was highest for scenarios that described actual harm occurring. Mean WTP across the scenarios ranged from $£ 45$ (95\% Cl £36 to £54) to £278 (95\% Cl $£ 200$ to £355). Several factors influenced both the value and likelihood of WTP, such as: income, known experience of medication errors, sex, field of work, marriage status, education level and employment status. Predictors of WTP were not, however, consistent across scenarios.

Conclusions This CV study highlights how the UK public value preventing medication errors. The findings from this study could be used to carry out a cost-benefit analysis which could inform implementation decisions on the use of technology to reduce medication administration errors in UK hospitals.

\section{INTRODUCTION}

Medication errors are common, with a recent review estimating that 237 million medication errors occurred across primary and
Strengths and limitations of this study

- First study to obtain UK public preferences for the prevention of hospital medication administration errors.

- Preferences obtained from a representative sample of the UK public which aligns with the interest of policy-makers who seek to represent the general public.

- The contingent valuation survey design and development adhered to internationally recognised methodological standards.

- Preference results may be subject to biases introduced from respondents' interpretation of scenarios.

- The online format of the survey may introduce bias to the results from a 'digital divide'.

secondary care settings and care homes every year in England. ${ }^{1}$ Over a quarter of these errors had the potential to cause moderate or severe harm. ${ }^{1}$ A review of internationally published studies of medication administration errors in hospitals and long-term care facilities reported a median error rate of $21.7 \%$ of administered medication doses in the UK $(5.5 \%$ when wrong time errors were excluded). ${ }^{2}$ Medication errors may result in harm or no harm to the patient (eg, if a medication was given a little late).

Harm caused because of medication use is known as an adverse drug event (ADE) and is formally defined as 'injury resulting from medical interventions related to a drug'. ${ }^{3}$ Potential ADEs are defined as medication errors that had the potential to cause harm but this did not occur (eg, a patient received a drug which they had a documented allergy to but no reaction occurred). ${ }^{4}$ The administration of medication may also result in an unexpected adverse reaction (eg, a rash caused by a previously unknown allergic reaction) known as a non-preventable ADE. ADEs can result in patient morbidity and mortality ${ }^{5}$ 
in addition to significant distress for their relatives and care providers. ${ }^{6}$ Furthermore, there is a substantial cost associated with preventable medication errors. This has been estimated to be over $£ 111$ million (2015/16 prices) annually for errors made in primary and secondary care in the UK. ${ }^{1}$

Interventions have been developed and implemented to reduce medication administration errors in hospitals. These include the use of health information technology, such as barcode medication administration systems to identify both the patient and the medication is correct at the administration stage. ${ }^{7-9}$ A systematic review reported a reduction in medication errors following implementation of a barcode administration system. ${ }^{10}$ There is, however, a lack of evidence around the impact of alternative tools to prevent medication administration errors, particularly in a UK setting.

The UK MedEye study ${ }^{11}$ was conducted to explore the impact of implementing a novel bedside medication verification system on medication administration errors in hospitals and value the benefit that individuals associated with avoiding such errors. These include patient health benefits, like maintaining their quality of life and nonhealth benefits, such as maintaining their trust in hospital systems and devices. ${ }^{12}$

One approach to measuring the value that patients place on preventing medication errors is by using stated preference techniques ${ }^{13}$; these are so called because individuals are asked to state their preferences regarding their willingness-to-pay (WTP) for the good or outcome under investigation (in this case, preventing medication error and resulting ADEs). Contingent valuation (CV) is a stated preference technique that involves the creation of a hypothetical market in which individuals are asked the maximum amount they would be willing to pay for a good. ${ }^{1415}$ The stated monetary amount is considered to represent the economic value placed on the good by the individual. ${ }^{16}$ Benefits valued using $\mathrm{CV}$ are not limited to direct health benefits, therefore, the CV method can also be appropriate when valuing health technologies incorporating non-health benefits. No previous studies have obtained stated preference valuations for preventing medication errors; however, the CV method has previously been used to value the benefit of avoiding adverse events associated with specific health conditions, such as anaemia ${ }^{17}$ and whooping cough. ${ }^{18}$ Given the gap in the current literature, we conducted a WTP study using the CV method to obtain a monetary value for the holistic benefit from the prevention of hospital medication administration errors.

\section{METHODS}

An online CV survey was developed with Dynata Ltd, a company who have considerable experience in survey development, distribution and data collection from the UK public.

\section{Survey development}

The survey was developed in five steps. Step 1: Seven hypothetical scenarios were developed for the survey by researchers at Newcastle University (SRH and LV) drawing on information from ADE literature ${ }^{19-21}$ (see online supplemental material A for descriptions of all scenarios). These were reviewed by two pharmacists, from Newcastle upon Tyne hospitals and Newcastle University, to ensure clinical accuracy of descriptions with different levels of harm: (Scenario 1) errors which have no potential to cause harm to the patient, (Scenarios 2-4) errors which have the potential to cause harm to the patient, and (Scenarios 5-7) errors which cause actual harm to the patient. Scenario 1 was included to explore whether people value preventing medication errors in hospital independent of clinical harm caused.

The potential to cause harm and actual harm scenario categories were each then further divided into three scenarios representing the severity of harm associated with each ADE: mild harm, moderate harm and severe harm (see figure 1). These were determined to reflect the severity distinctions of both potential and actual ADEs avoided by preventing medication administration errors provided in the literature. ${ }^{19-21}$ As medication errors which fall within the 'potential to cause harm' category occur more commonly than those in the 'actual harm' category, ${ }^{7}$ there remained an empirical question of whether people would value preventing medication errors which would have only the potential to cause harm differently to those which would cause actual harm.

Step 2: Two patient and public involvement (PPI) sessions were held; the first $(n=3)$ to help refine the wording of the survey instructions and scenarios and the second $(n=4)$ to identify the most appropriate type of

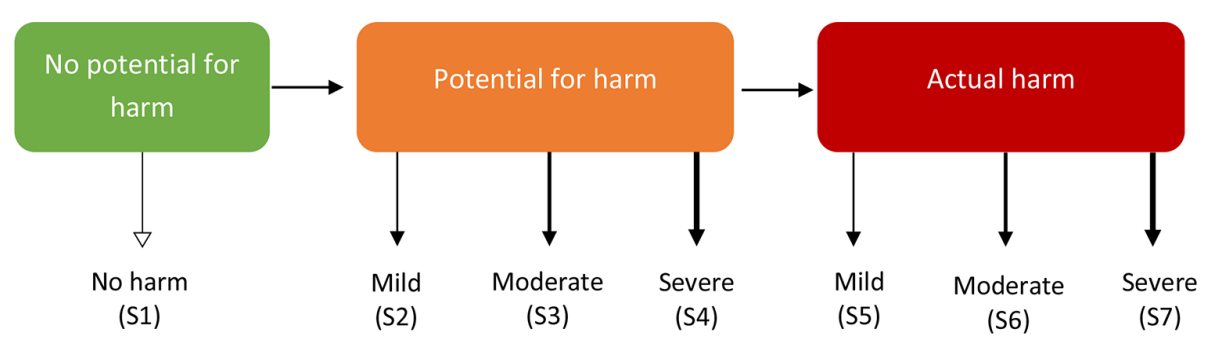

*S=Scenario

Figure 1 Outline of the seven medication error scenarios. 
payment to use (ie, the payment vehicle) ${ }^{1522}$ and identify the most appropriate way to ask the CV question (ie, the elicitation method). ${ }^{1522}$ The PPI members suggested that a 'donation to your local hospital trust' was the preferable payment vehicle compared with additional tax contributions or a one-off payment. When exploring different elicitation methods, the PPI members found that asking an open-ended question, for example, 'How much would you be willing to pay to prevent the medication error?', was difficult to consider. Alternative approaches were presented, such as a payment card method ${ }^{23}$ (ie, a list of monetary amounts is presented and respondents select the amounts they are WTP) and an iterative bidding technique $^{1523}$ (ie, respondents are offered an initial monetary amount and, subject to the respondent's WTP response, a follow-up amount is offered which is either lower or higher than the initial monetary amount. ${ }^{22}$ There was no strong preference from the PPI members for either method, thus, a version of the payment card method (the random card sort technique ${ }^{24}$ was chosen for the survey.

Step 3: The survey was then tested on a range of volunteers $(n=14)$ with different occupations (eg, postgraduate students, pharmacists, clinicians and professional services staff) to ensure that the range of values presented in the random card sort was appropriate for the good being valued. The final range of values used in the survey was: $£ 1, £ 5, £ 10$, £25, £50, £75, £100, £150, £200, £300, £500, $£ 750, £ 1000$.

Step 4: The survey was further refined by adding a logic test (The logic test comprised of one question after each scenario was presented which asked respondents whether any harm is caused because of the medication error described in the scenario. Correct answers which passed the logic test were 'no harm' for scenarios 1-4, and 'yes, harm caused' for scenarios 5-7) after each scenario to ensure respondents understood whether actual harm was caused because of the medication error in each case. Respondents were then asked whether they would be willing to pay to prevent each medication error. Respondents who were unwilling to pay were asked to select their reason from a list of five possible options (see box 1) and had an opportunity to provide a free text response under 'other'. The justifications selected for unwillingness to pay were used to categorise responses as either a protest response (ie, the respondent valued preventing the medication error but was unwilling to pay for another reason ${ }^{25}$ or a true zero valuation (ie, a reason

\section{Box 1 Reasons for unwillingness to pay}

1. Avoiding the medication mistake is not valuable to me.

2. Avoiding the medication mistake is valuable to me but I can't afford it.

3. I do not think donations to my local hospital trust should fund this.

4. Avoiding the medication mistake is valuable to me but it should be funded by existing government budgets.

5. Other. indicating that a respondent truly did not value the intervention). The options 'Avoiding the medication mistake is valuable to me but it should be funded by existing government budgets' and 'I do not think donations to my local hospital trust should fund this' were considered protests against the method of payment. The free-text responses were examined independently by two members of the research team (SRH and LV) who categorised each response as either a protest or a true zero. Where opinions differed for response categorisation, a final decision was made via discussion between the two researchers and no third-party input was required.

Respondents who indicated WTP to prevent the medication error completed a random card sort in which monetary amounts were displayed randomly and respondents would indicate whether they 'would pay', 'would maybe pay' or 'would not pay' each amount in turn. The random card sort was introduced to allow respondents to think through how they value preventing each medication error before being asked an open-ended question: 'What is the MAXIMUM value you would be willing to pay as a one-off donation to your local hospital trust to avoid the medication mistake?'. The respondent's choices of monetary values that they were willing/not willing-to-pay during the random card sort were displayed when asking the open-ended question, to help guide the respondent to state their maximum WTP. The open-ended question allowed for greater sensitivity to individual WTP and provided continuous rather than interval data for analysis.

Step 5: An online pilot of the survey was conducted by Dynata to their UK panel in February 2020, which obtained responses from 166 respondents. Small changes were made to the scenario descriptions (ie, emphasising some text in bold and adding a clarification of the harm associated with each error in the scenario title) in response to the pilot, predominantly to improve the proportion of respondents passing the logic test. The fully developed survey was then finalised.

\section{Patient and public involvement}

As described above, two PPI sessions were held to inform the design of the CV survey.

\section{Data collection}

Dynata distributed the online survey to their UK panel on 2 March 2020 and received all responses on 18 March 2020. The sample collected was representative of the adult UK public according to age, sex and occupational group. In addition to the WTP questions, demographic characteristics were also collected (see table 1 for all characteristics collected). A required sample size of 502 was calculated following the sample size calculation recommended by Mitchell and Carson ${ }^{23}$ (see online supplemental material $\mathrm{B}$ for full details of the sample size calculation). The sample size was inflated to account for the proportion of data that would not count towards analysis, using data on failed logic responses and protests from the soft launch, resulting in a desired sample size of 996. 
Table 1 Characteristics of full initial sample

\begin{tabular}{|c|c|c|c|}
\hline \multirow{2}{*}{$\begin{array}{l}\text { Respondent } \\
\text { characteristic }\end{array}$} & \multicolumn{2}{|c|}{ Initial sample ( $\mathrm{N}=1001)$} & \multirow{2}{*}{$\begin{array}{l}\text { UK national } \\
\text { proportions } †, \%\end{array}$} \\
\hline & \multicolumn{2}{|c|}{ Frequency (\%) } & \\
\hline \multicolumn{4}{|l|}{ Sex } \\
\hline Male & 498 & $(49.8)$ & 48.7 \\
\hline Female & 502 & $(50.1)$ & 51.3 \\
\hline $\begin{array}{l}\text { Prefer not to } \\
\text { say }\end{array}$ & 1 & $(0.1)$ & - \\
\hline \multicolumn{4}{|l|}{ Age } \\
\hline $18-24$ & 153 & (15.3) & 14.8 \\
\hline $25-34$ & 161 & $(16.1)$ & 16.6 \\
\hline $35-44$ & 170 & (17.0) & 17.3 \\
\hline $45-54$ & 175 & $(17.5)$ & 17.2 \\
\hline $55-64$ & 156 & $(15.6)$ & 14.6 \\
\hline $65+$ & 186 & $(18.6)$ & 19.5 \\
\hline
\end{tabular}

Region

\begin{tabular}{lrrr} 
England & 852 & $(85.1)$ & 84 \\
\hline Scotland & 82 & $(8.2)$ & 8.1 \\
Wales & 48 & $(4.8)$ & 4.7 \\
$\begin{array}{l}\text { Northern } \\
\text { Ireland }\end{array}$ & 19 & $(1.9)$ & 2.7 \\
\hline
\end{tabular}

Occupational groupł

$\begin{array}{lrrr}\text { A } & 56 & (5.6) & 4 \\ \text { B } & 223 & (22.3) & 23 \\ \text { C1 } & 288 & (28.8) & 28 \\ \text { C2 } & 191 & (19.1) & 20 \\ \text { D } & 125 & (12.5) & 15 \\ \text { E } & 118 & (11.8) & 10\end{array}$

\section{Marriage status}

\begin{tabular}{lccc}
$\begin{array}{l}\text { Married/ } \\
\text { cohabiting }\end{array}$ & 539 & $(53.8)$ & 51.2 \\
Single & 340 & $(34.0)$ & 34.4 \\
$\begin{array}{l}\text { Divorced/ } \\
\text { widowed }\end{array}$ & 121 & $(12.1)$ & 14.4 \\
$\begin{array}{l}\text { Prefer not to } \\
\text { say }\end{array}$ & 1 & $(0.1)$ & - \\
$\begin{array}{l}\text { Employment status } \\
\text { Full time }\end{array}$ & 378 & & \\
$\begin{array}{l}\text { Part time } \\
\text { Self employed }\end{array}$ & 731 & $(37.8)$ & - \\
Unemployed & 117 & $(13.1)$ & - \\
Retired & 200 & $(7.3)$ & - \\
$\begin{array}{l}\text { Full-time } \\
\text { student }\end{array}$ & 58 & $(11.7)$ & - \\
$\begin{array}{l}\text { Part-time } \\
\text { student }\end{array}$ & 2 & $(20.0)$ & - \\
Other & 42 & $(0.8)$ & - \\
Working in the health sector & & - \\
Yes & 113 & $(11.3)$ & - \\
\hline
\end{tabular}

Continued
Table 1 Continued

\begin{tabular}{|c|c|c|}
\hline \multirow{2}{*}{$\begin{array}{l}\text { Respondent } \\
\text { characteristic }\end{array}$} & Initial sample $(\mathrm{N}=1001)$ & \multirow{2}{*}{$\begin{array}{l}\text { UK national } \\
\text { proportionst, \% }\end{array}$} \\
\hline & Frequency (\%) & \\
\hline No & (66.8) & - \\
\hline
\end{tabular}

Not applicable 219

Studying a health-related field

$\begin{array}{lrr}\text { Yes } & 8 & (0.8) \\ \text { No } & 52 & (5.2) \\ \text { Not applicable } & 941 & (94.0)\end{array}$

Education

\begin{tabular}{|c|c|c|c|}
\hline Degree & 363 & (36.3) & - \\
\hline $\begin{array}{l}\text { Higher } \\
\text { education } \\
\text { below degree }\end{array}$ & 114 & (11.4) & - \\
\hline A-level & 220 & (22.0) & - \\
\hline $\operatorname{GCSE} A^{*}-C$ & 221 & (22.1) & - \\
\hline GCSE D-G & 47 & (4.7) & - \\
\hline Foreign qual & 2 & $(0.2)$ & - \\
\hline $\begin{array}{l}\text { No formal } \\
\text { qualifications }\end{array}$ & 34 & (3.4) & - \\
\hline
\end{tabular}

Annual household income $(£)$

\begin{tabular}{lrrr} 
OK-12K & 110 & $(11.0)$ & - \\
\hline $12 \mathrm{~K}-20 \mathrm{~K}$ & 167 & $(16.7)$ & - \\
\hline $20 \mathrm{~K}-30 \mathrm{~K}$ & 220 & $(22.0)$ & - \\
$30 \mathrm{~K}-40 \mathrm{~K}$ & 166 & $(16.6)$ & - \\
$40 \mathrm{~K}-50 \mathrm{~K}$ & 116 & $(11.6)$ & - \\
50K-70K & 89 & $(8.9)$ & - \\
$70 \mathrm{~K}-100 \mathrm{~K}$ & 64 & $(6.4)$ & - \\
100K† & 16 & $(1.6)$ & - \\
Prefer not to & 40 & $(4.0)$ & - \\
say & & &
\end{tabular}
Unknown
13
(1.3)

Known personal experience of a medication mistake

$\begin{array}{lrrr}\text { Experience } & 74 & (7.4) & - \\ \text { No experience } & 880 & (87.9) & - \\ \text { Unsure } & 47 & (4.7) & -\end{array}$

Harm suffered from the mistake

$\begin{array}{lrrr}\text { Harm } & 29 & (39.2)^{\star} & - \\ \text { No harm } & 41 & (55.4)^{\star} & - \\ \text { Unsure } & 4 & (5.4)^{\star} & -\end{array}$

Friend or family member known experience of a medication mistake

$\begin{array}{lrll}\text { Experience } & 174 & (17.4) & - \\ \text { No experience } & 729 & (72.8 \%) & - \\ \text { Unsure } & 98 & (9.8 \%) & -\end{array}$

Harm suffered from the mistake

\begin{tabular}{lrrrr} 
Harm & 102 & $(58.6 \%)^{*}$ & \\
No harm & 51 & $(29.3 \%)^{*}$ & & \\
\hline & & & & Continued
\end{tabular}


Table 1 Continued

\begin{tabular}{cccl}
\hline \multirow{2}{*}{$\begin{array}{l}\text { Respondent } \\
\text { characteristic }\end{array}$} & \multicolumn{2}{l}{ Initial sample (N=1001) } & $\begin{array}{l}\text { UK national } \\
\text { proportionst, \% }\end{array}$ \\
\hline Unsure & 21 & $(12.1 \%)^{*}$ & - \\
\hline
\end{tabular}

*\% of those reporting personal/familial experience of medication mistake

†National proportions reported where available. Marriage status for England and Wales only

$\ddagger$ Occupational groups: $\mathrm{A}=$ Higher managerial, administrative and professional, $\mathrm{B}=$ Intermediate managerial, administrative and professional, $\mathrm{C} 1=$ Supervisory, clerical and junior managerial, administrative and professional, C2=Skilled manual workers, $\mathrm{D}=$ Semi-skilled and unskilled manual workers, $\mathrm{E}=$ State pensioners, casual and lowest grade workers, unemployed with state benefits only.

GCSE, General Certificate of Secondary Education.

\section{Data analysis}

Survey data were analysed using statistical software STATA V.15. ${ }^{26}$ Descriptive statistics were conducted to calculate mean and median WTP. Protest responses were removed from the sample prior to analysis following conventional practice, ${ }^{27}$ so as not to downwardly bias WTP estimates. Base-case analysis also excluded responses which failed the logic test for each scenario. Sensitivity analyses were conducted to explore the impact on mean WTP from trimming the highest $1 \%$ of values and from including responses that failed the logic test.

Regression analysis was conducted to identify predictors of WTP. Due to a large proportion of zero values (from respondents who state unwillingness to pay) and a skewed data distribution, standard ordinary least squares estimators would have provided biased and inconsistent estimates. ${ }^{28}$ Two-part models have been recommended for continuous data with a spike at zero. ${ }^{29} \mathrm{~A}$ two-part model was employed in order to take account of the zero WTP values in the regression analysis. ${ }^{30}$ The two-part model used respondents' WTP value for each scenario as the dependent variable (see online supplemental material $\mathrm{C}$ for details of predictor variables); logistic regression first modelled the probability of a respondent being willing to pay to avoid the medication error (ie, those unwilling to pay are allocated a WTP value of $£ 0$ ) and a linear regression (generalised linear model, GLM) modelled WTP value conditional on the respondent being willing to pay (ie, having a WTP value $>£ 0$ ).

A subgroup analysis was conducted which included respondents who failed the logic test for scenarios 1-4 (ie, respondents who believed harm was caused by the medication errors which had no potential to cause harm and potential to cause harm) but also reported personal experience of a medication error. This subgroup analysis was prompted because a comparison of characteristics between respondents who passed and failed logic tests showed that respondents failing the logic tests for scenarios 1-4 (There was no difference in medication error experience between those who passed and failed the logic test for scenarios 5-7) were more likely to report known experience of prior error. Therefore, the basecase analysis for these scenarios was potentially biased towards individuals who had no known experience of a medication error.

\section{RESULTS}

In total, 1001 responses were received to the survey. Table 1 outlines the demographic characteristics of the full sample survey participants (see online supplemental table S1 for characteristics of the sample included in analysis for each scenario separately). Most of the sample had no known personal or familial experience of medication errors and did not work in the health sector. Similar proportions of respondents reported household incomes of less than $£ 20000$ (28\%) or greater than $£ 40000$ (29\%) and the largest proportion reported household incomes between $£ 20000$ and $£ 40000$ (39\%).

Across the scenarios, $56 \%-88 \%$ of respondents passed the logic test and were included in the base-case analysis (see table 2). Fewer respondents passed the logic test for the potential harm scenarios than for the actual harm scenarios. Table 2 describes the number and type of response for each scenario. There was a similar proportion of protest responses across all scenarios in the base-case analysis ( $45 \%$ of the sample); however, the proportion of respondents willing to pay to prevent the medication error increased between the potential and actual harm scenarios and increased as the severity of the ADE and medication error increased.

Both mean and median WTP were greater than zero (henceforth, 'positive') for all scenarios. The lower bound of the $95 \%$ CIs around mean WTP were substantially greater than zero for all scenarios, which suggests with confidence that true mean WTP is positive. Both mean and median WTP increase as severity of ADE increases and between potential and actual harm scenarios. Mean WTP ranged from $£ 45$ (95\% CI $£ 36$ to $£ 54)$ to prevent a medication error which causes no harm, to $£ 278$ (95\% CI $£ 200$ to $£ 355$ ) to prevent a medication error which causes life-threatening actual harm (see table 3).

The $95 \%$ CIs were widest for the larger mean WTP values, which suggests the presence of outlier WTP values for the most severe actual ADE scenarios. The comparable $95 \%$ CIs when the top $1 \%$ of WTP values were trimmed are substantially narrower, validating the theory that a few, large outliers in the base-case sample skewed the results. However, for the trimmed WTP sample, there is evidence that both mean and median WTP remain greater than zero (see table 3 ).

Including failed logic responses increased estimates of mean and median WTP for the no-harm and potential harm scenarios and reduced estimates for the actual harm scenarios (see table 3). This result is expected given that incorrect logic responses to the potential ADE scenarios anticipated harm from the medication error, and vice 
Table 2 Initial sample and unwillingness-to-pay (WTP) responses

\begin{tabular}{|c|c|c|c|c|c|c|c|}
\hline Scenarios & $\begin{array}{l}\text { No } \\
\text { potential } \\
\text { for harm }\end{array}$ & $\begin{array}{l}\text { Potential } \\
\text { harm } \\
\text { (mild) }\end{array}$ & $\begin{array}{l}\text { Potential harm } \\
\text { (moderate) }\end{array}$ & $\begin{array}{l}\text { Potential } \\
\text { harm } \\
\text { (severe) }\end{array}$ & $\begin{array}{l}\text { Actual } \\
\text { harm } \\
\text { (mild) }\end{array}$ & $\begin{array}{l}\text { Actual harm } \\
\text { (moderate) }\end{array}$ & $\begin{array}{l}\text { Actual harm } \\
\text { (severe) }\end{array}$ \\
\hline Initial sample (N) & 1001 & 1001 & 1001 & 1001 & 1001 & 1001 & 1001 \\
\hline $\begin{array}{l}\text { No passing logic test } \\
(\%)\end{array}$ & $\begin{array}{l}867 \\
(86.6)\end{array}$ & $\begin{array}{l}616 \\
(61.5)\end{array}$ & $\begin{array}{l}568 \\
(56.7)\end{array}$ & $\begin{array}{l}565 \\
(56.4)\end{array}$ & $\begin{array}{l}787 \\
(78.6)\end{array}$ & $\begin{array}{l}865 \\
(86.4)\end{array}$ & $\begin{array}{l}885 \\
(88.4)\end{array}$ \\
\hline $\begin{array}{l}\text { No of protest-zero } \\
\text { WTP responses* }\end{array}$ & 344 & 277 & 274 & 266 & 358 & 383 & 379 \\
\hline $\begin{array}{l}\text { No of positive WTP } \\
\text { responses* }\end{array}$ & 284 & 199 & 192 & 209 & 336 & 387 & 422 \\
\hline $\begin{array}{l}\text { No of true zero WTP } \\
\text { responses }\end{array}$ & 239 & 140 & 102 & 90 & 93 & 95 & 84 \\
\hline $\begin{array}{l}\text { No excluded for } \\
\text { other reasons, for } \\
\text { example, clear } \\
\text { misunderstanding } \\
\text { of WTP question or } \\
\text { scenario description }\end{array}$ & 10 & 8 & 6 & 6 & 8 & 14 & 0 \\
\hline
\end{tabular}

$\begin{aligned} & \text { Reasons for unwillingness to pay }(\mathrm{N}) \dagger \\ & \begin{array}{l}\text { Avoiding the } \\ \text { medication mistake is }\end{array} \\ & \text { not valuable to me }\end{aligned}$
$\begin{aligned} & \text { Avoiding the } \\ & \text { medication mistake is } \\ & \text { valuable to me but I } \\ & \text { can't afford it }\end{aligned}$
$\begin{aligned} & \text { I do not think } \\ & \text { donations to my local } \\ & \text { hospital trust should } \\ & \text { fund this }\end{aligned}$
$\begin{aligned} & \text { Avoiding the } \\ & \text { medication mistake is } \\ & \text { valuable to me but it } \\ & \text { should be funded by } \\ & \text { existing government } \\ & \text { budgets }\end{aligned}$

*Only respondents who pass logic test included in numbers

†ncludes both protest-zero and true-zero responses of respondents who passed the logic test. Total number of participants included in the base case analysis for each scenario is calculated as the number passing the logic test minus the number of protest zero WTP responses,

since protesters are removed from the sample prior to analysis

versa for the actual harm ADE. It is logical that respondents anticipating harm from the medication error in the potential harm scenarios may have been willing to pay more than those correctly anticipating no harm occurring. The converse would be true for the actual harm ADEs.

\section{Regression analysis}

The base-case regression analysis results are reported in table 4 . The logit columns of table 4 report the odds of a respondent being willing to pay to prevent the medication error in each scenario and the GLM columns report the impact of each predictor variable on the WTP amount offered, conditional on the respondent being willing to pay to prevent the medication error.

\section{Factors predicting likelihood of WTP}

In the base-case analysis, there is evidence that having a family member who had experienced a medication error increased respondents' likelihood of paying to prevent a potentially harmful medication error (OR 2.5-3, p<0.05), as did having an annual household income greater than $£ 40000$ compared with between $£ 20000$ and $£ 40000$ (OR: 2, $\mathrm{p}<0.05$ ). Table 4 also demonstrates evidence that being male $(p<0.01)$, working or studying in a non-health sector field $(\mathrm{p}<0.05)$, being married $(\mathrm{p}<0.05)$, and having 
Table 3 Mean and median WTP for base-case and sensitivity analyses, GBP£

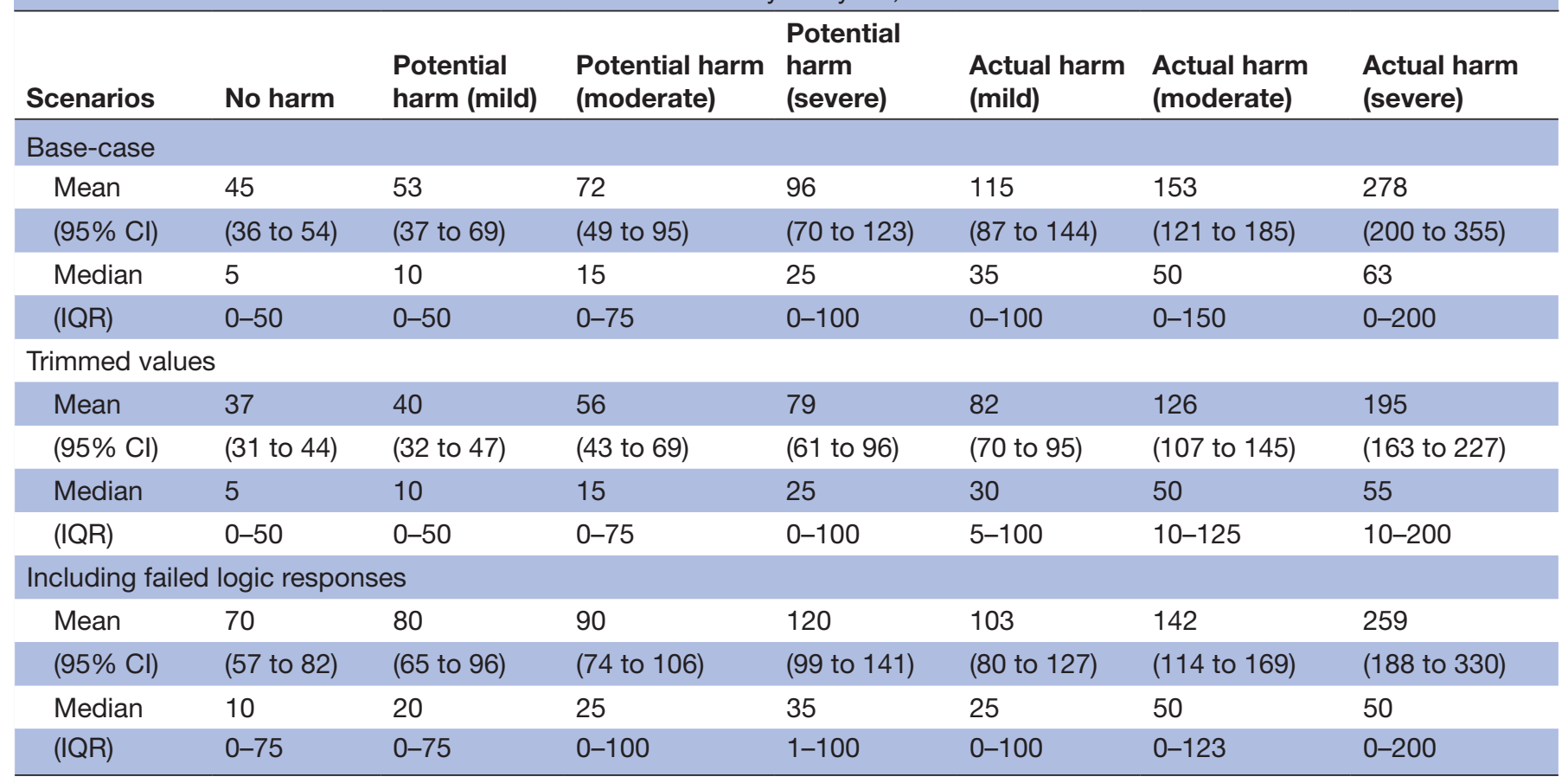

WTP, willingness-to-pay.

higher education compared with standard qualifications $(p<0.01)$ all increased the odds of being willing to pay to prevent a medication error for at least one scenario. However, evidence is not consistent across all scenarios. There is also evidence that having an annual household income of less than $£ 20000$ compared with between $£ 20$ 000 and $£ 40000$ decreased the odds of WTP a positive amount (OR 0.49-0.53, $\mathrm{p}<0.05$ ).

\section{Factors predicting a lower WTP amount}

Respondents who are unemployed $(\mathrm{p}<0.05)$, unpaid workers $(\mathrm{p}<0.01)$, female $(\mathrm{p}<0.01)$ or unsure about their medication error experience $(\mathrm{p}<0.05)$ offered lower WTP amounts than their comparative respondents to prevent actual harmful errors (see table 4 for base factors). Those studying in a health-related field also offered less to prevent a mild, potentially harmful error $(\mathrm{p}<0.05)$.

\section{Factors predicting a higher WTP amount}

Having a family member who had experienced a medication error increased the WTP amount to prevent severely harmful errors $(\mathrm{p}<0.05)$ while young respondents (compared with those aged 35-65) offered more to prevent errors which cause no, or potentially moderate, harm $(p<0.05)$. Respondents with higher education $(p<0.01)$ and annual household incomes above $£ 40000$ $(p<0.01)$ were willing to pay higher amounts than their comparative respondents to prevent actual harmful errors. For most of the scenarios, there is no evidence that respondents with the lowest household incomes offered different WTP amounts to respondents in the mid-range household income category (£20 000-£40 000), except for preventing moderately harmful errors in which this group offered a higher WTP amount.

\section{Subgroup analysis}

The subgroup analysis is reported in online supplemental table S2. This analysis includes respondents who failed the logic test for the first four scenarios (in which failure was characterised by participants believing harm is caused in the four scenarios in which no ADE occurs) but reported personal experience of a medication error. There are very few changes to variables identified as predictors of likelihood or value of WTP between the base-case and subgroup analyses, apart from the impact of personal medication error experience and familial medication error experience. Online supplemental table S2 shows that in the no potential to cause harm and both potential for mild and moderate harm scenarios, known personal medication error experience increased the odds of WTP to prevent the medication error substantially (OR 2.65-3.67; $\mathrm{p}<0.01)$.

The evidence of impact of known familial experience of a medication error is, however, reduced in the subgroup analysis compared with the base case; there is only evidence of an increase in odds of WTP for one scenario (potential for mild harm) compared with all three potential harm scenarios in the base case.

\section{DISCUSSION}

The results from this CV study suggest that the UK public value preventing medication errors, even in situations where no ADE occurred. However, a smaller proportion 


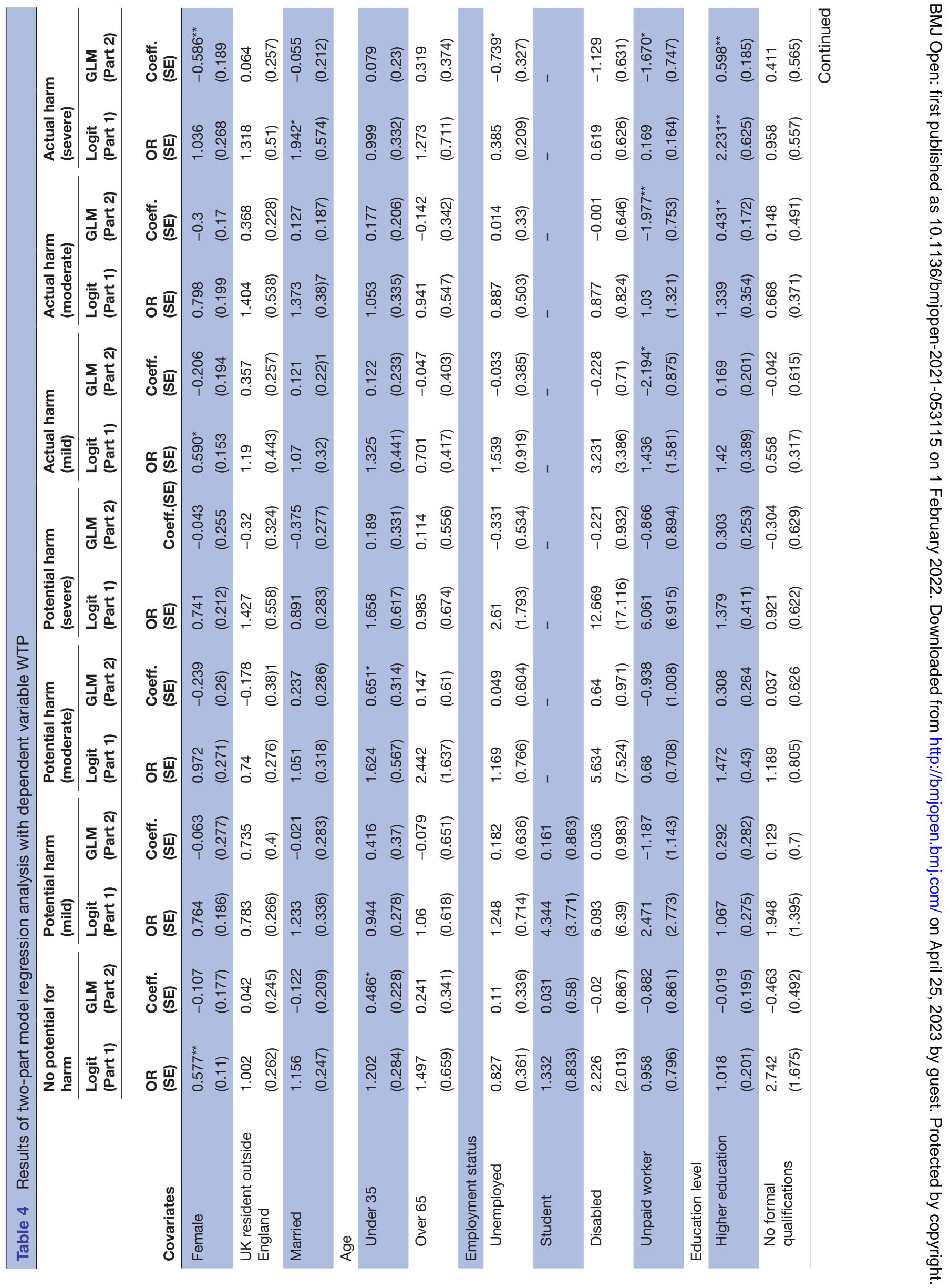




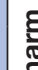

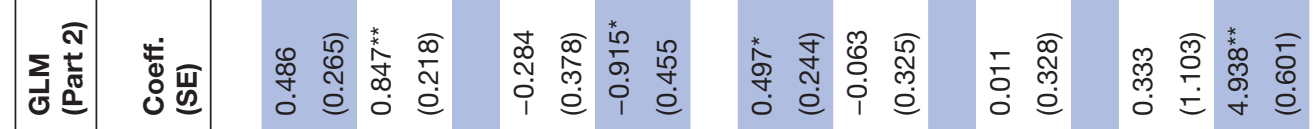

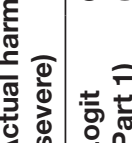
过迎

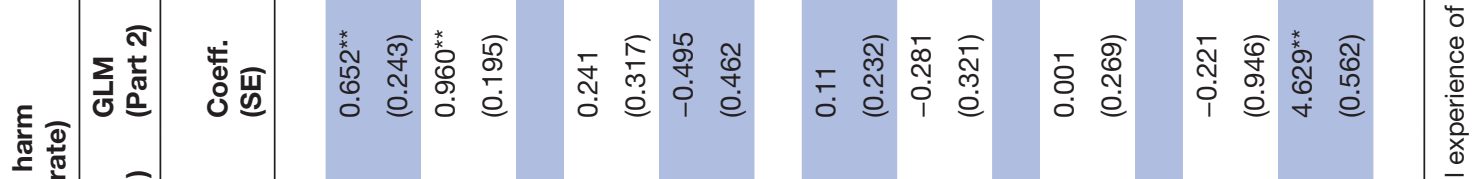

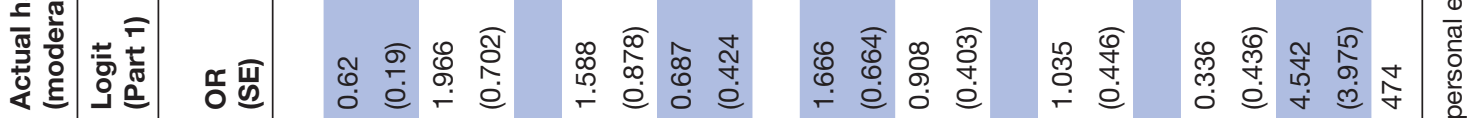

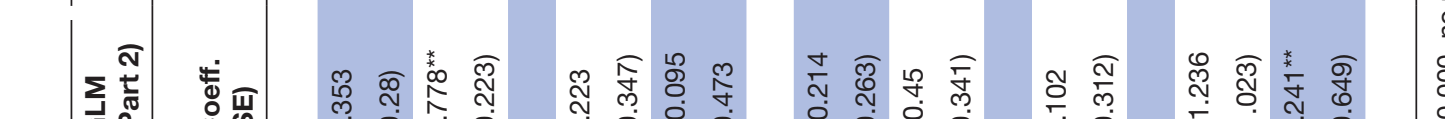
ह ए

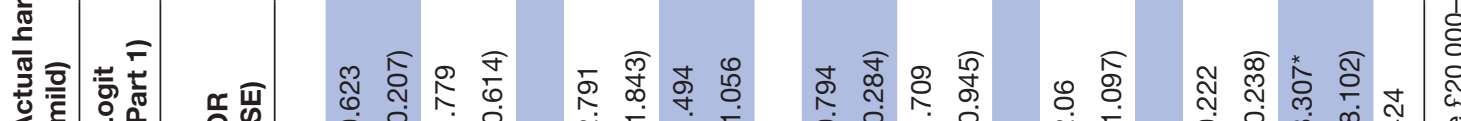

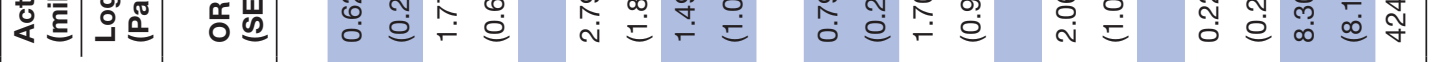

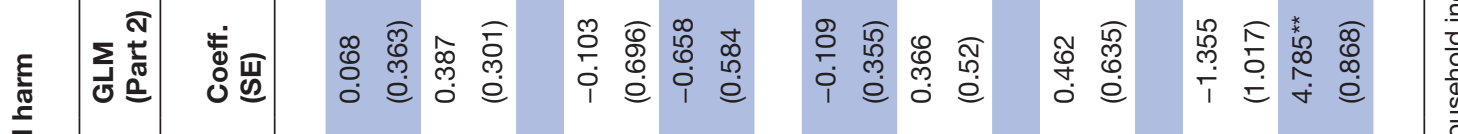
ஜ

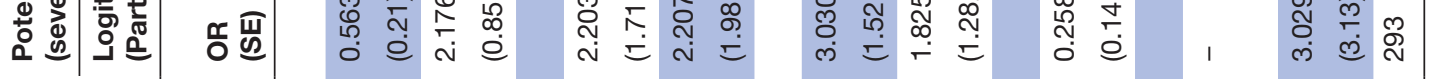

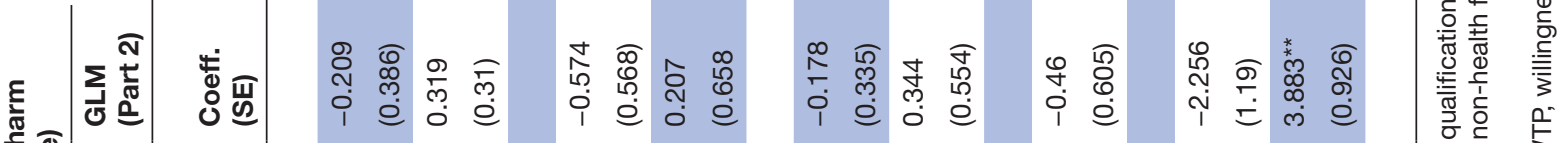
焉

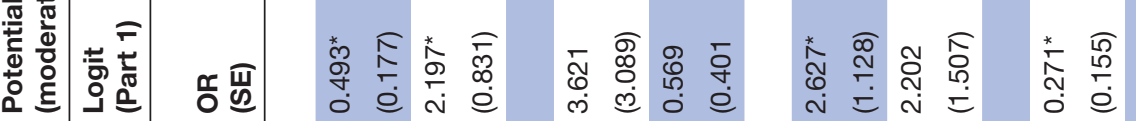

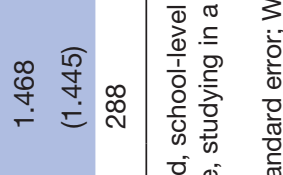

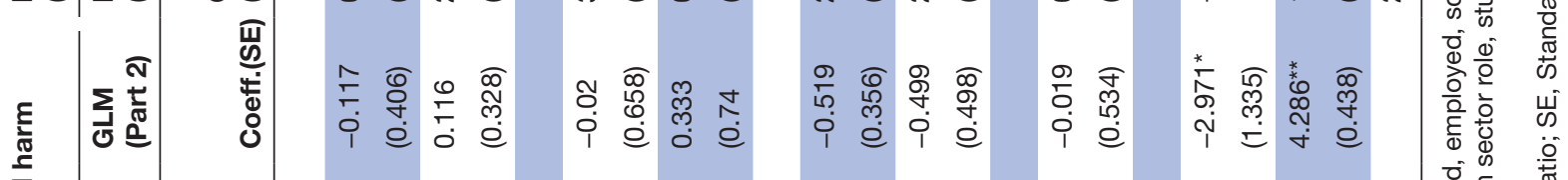
焉

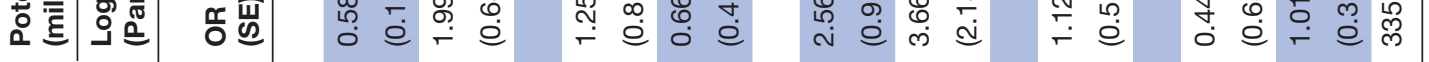

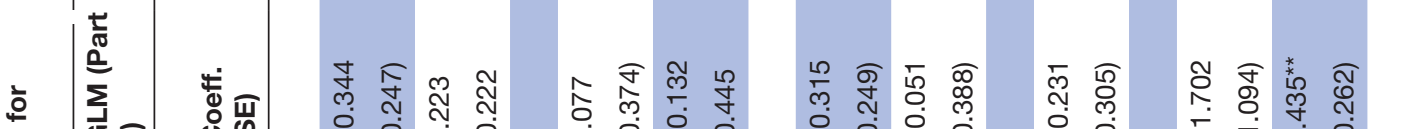

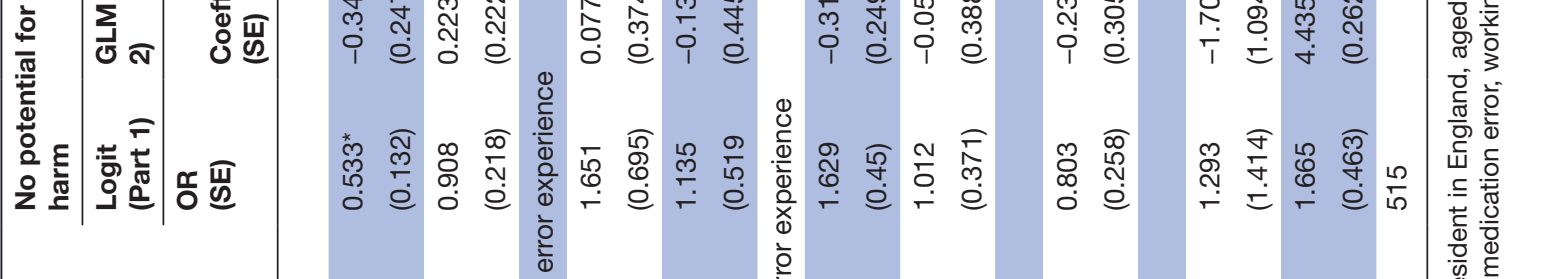
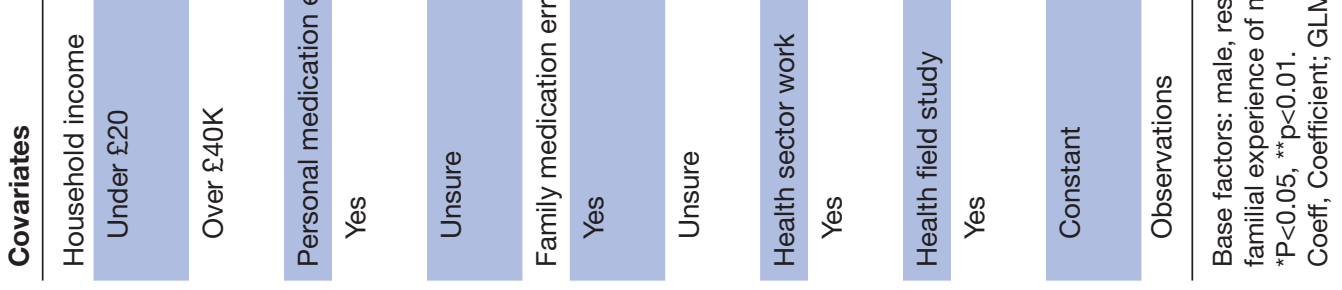
of respondents valued preventing medication errors which have no potential to cause an ADE (scenario 1: $54 \%$ ) compared with preventing errors which cause actual harm (scenarios 5-7: 80\%) and errors with potential to cause harm (scenarios 2-4: $65 \%$ ). This provides a degree of face validity to the study as it was expected that more respondents would value the prevention of errors that could cause harm than errors that are not associated with any harm to patients. Despite the lower proportion of respondents valuing errors causing no harm compared with preventing those resulting in ADEs, over half of the analytical sample did value the prevention of errors which had little to no likelihood of resulting in harm. This suggests that the UK public attribute, and positively value, non-health benefits from the prevention of medication errors, such as increased trust in healthcare provision. Thus, low-cost interventions that can prevent medication administration errors, regardless of the potential for harm prevented as a result, may still be efficient from a UK societal perspective due to the value placed on nonhealth benefits associated with preventing medication errors.

The subgroup analysis results further substantiate this conclusion. This analysis was conducted after identifying evidence of a difference in known personal medication error experience between respondents who passed and those who failed the logic test for the first four scenarios (ie, those in which no ADE occurs as a results of the medication error). It is assumed that individuals who have experienced a medication error personally are more informed about the impacts of such errors than individuals who have no personal experience. The failures in the logic test could be due to misunderstanding the question or misreading the scenarios, however, the significant difference between passes and failures characterised by individuals with experience in medication errors suggests that these respondents are aware of harms caused to patients from medication errors, regardless of whether an ADE occurs. One explanation could be that respondents who have experienced medication errors personally encountered non-health-related harms as a result. To explore this theory, respondents who failed the logic test for the first four scenarios and reported personal experience of a medication error were included in an additional regression analysis (all other logic failures remained excluded). This additional analysis demonstrated that personal medication error experience increased the likelihood of a respondent being willing to pay to prevent medication errors in the scenarios in which no actual ADE occurs as a result. These results further support a theory that those with personal medication error experience perceive non-health-related benefits from preventing medication errors as those individuals are more likely to value error prevention than individuals without similar experience in situations where errors do not result in an ADE.

Several other predictors of WTP were identified in the base-case regression analysis; however, these were not consistent across all scenarios, suggesting that the respondent characteristics examined in our analysis did not largely drive decisions on WTP. There may be other respondent characteristics that predict WTP to prevent medication administration errors that were not analysed in this study due to limitations in our data collection, such as participants' medication regimes, however, it was beyond the scope of our survey to collect this information. One consistent predictor of WTP was household income; there was evidence that respondents in the highest household income group (over $£ 40000$ annually) were consistently either more willing to pay to prevent medication errors or offer a higher WTP value for all scenarios except the 'no harm' scenario. Conversely, respondents in the lowest household income group (less than $£ 20000$ annually) were less likely to pay to prevent the medication errors, although the evidence for this was inconsistent (only scenarios 1 and 3 ). The link between ability to pay and WTP is expected in CV studies as the greater an individual's ability to pay, the greater both their likelihood of WTP and the value offered can be. Therefore, this finding indicates theoretical validity of the survey. ${ }^{31-33}$

Although the survey produced skewed data, which is common in CV surveys, ${ }^{34}$ with a substantial proportion of zeros, mean and median WTP were consistently and confidently positive across all scenarios. Trimming the top $1 \%$ of values to remove any potential outliers did not impact median WTP and mean WTP was reduced slightly, however, CIs remained substantially greater than zero. The findings of this study, with regard to the UK public valuing the prevention of medication errors, are considered robust.

The CV survey design and development adhered to internationally recognised methodological standards ${ }^{35} 36$ and the study sought to seek the views of a representative sample of the UK public. Thorough pilot testing allowed us to refine and simplify the survey. Furthermore, recent literature has reported that the random card sort technique, which was used in this survey, may produce more valid responses than the standard payment card method. ${ }^{37}$ Thus, the choice of this elicitation method over the standard payment card method adds to the validity of the results. In addition, asking open-ended questions without any context has been demonstrated to be cognitively burdensome $\mathrm{e}^{15}$ and has potential to result in large proportions of non-responses, zero responses and outliers. ${ }^{23}$ Therefore, conducting the random card sort task prior to asking the open-ended question was intended to minimise some of these biases while enabling more granular WTP responses from the open-ended question compared with responses from the random card sort task alone. However, the findings of our study should be interpreted in the light of some limitations.

Potential biases may have been introduced from respondents' interpretation of scenarios relating to details that were not included in the scenarios such as the duration of symptoms or likelihood of ADE occurrence. The heterogeneity of WTP responses could be explained by different interpretations of how long symptoms would 
last or the probability of symptoms occurring, and the extent of the negative impact the medication errors could have on patient well-being. Additionally, the construction of the survey itself may have introduced bias from the order in which scenarios were presented ${ }^{38}$ and the payment vehicle used. ${ }^{23} 39$ The scenarios were presented in the same order to each participant (no potential for harm, potential harm increasing in severity, then actual harm increasing in severity) and there were some objections to the payment vehicle from respondents, although these responses were removed from the analysis as protest zeros. Both the order of the scenarios presented, and the payment vehicle, were tested in PPI sessions and the final decisions based on feedback from the public representatives' feedback. The use of online survey panels may have limited the findings of our study by excluding members of the public who have not joined the market research panel used by Dynata to recruit respondents. In addition, the survey was not available to individuals without access to the internet. There may be differences in the characteristics of individuals on either side of the digital divide, thus, potentially biasing the results against those unable to participate due to access limitations.

\section{CONCLUSION}

This study has identified that the UK public value preventing medication errors, even in instances where no harm occurs. The value placed on preventing medication errors increases as the level of harm occurring due to error increases. Individuals with higher household income are more likely to be WTP to prevent a medication error and will offer greater amounts than individuals with lower incomes and known personal experience of a medication error had an impact on respondents' WTP to prevent medication errors in a subgroup analysis. Other factors predict increased likelihood and/or higher value of WTP (ie, higher education, being male, working or studying in a non-health sector field, being married, having family medication error experience, and being aged $<35$ years) however, these are not consistent across all scenarios. Alternatively, several factors predicted lower WTP offers, that is, unemployment or being in unpaid work, being female, studying in a health-related field and being unsure about medication error experience. Similarly, these factors were inconsistent predictors across all scenarios. Sensitivity analysis did not alter median WTP substantially and mean values were reduced when data were trimmed and outliers removed. Mean WTP and 95\% CIs remained substantially greater than zero in all sensitivity analyses, therefore, our conclusions regarding the value placed on preventing medication errors remain and the findings of this study provide reliable information on the value to the UK public of preventing medication errors.

This study has potential to impact future practice in medication administration in hospitals in the UK as the WTP findings from this study can be used to carry-out a cost-benefit analysis ${ }^{34}$ to explore the net monetary benefits of interventions to prevent medication errors in hospitals. The cost-benefit analysis could inform policy-makers' decisions regarding implementation of medication-error prevention interventions.

Acknowledgements The authors would like to thank Neil Watson for his assistance in developing the scenarios for the survey and Dr Laura Ternent for her assistance in the design of the survey. We would also like to thank all the members of the PPI group who provided insight at the focus groups and all those who assisted in pilot testing the survey. We would finally like to thank the survey respondents for giving their time to complete the survey.

Contributors SRH contributed to the design of the study, data collection, data analysis and write-up of the paper. NB contributed to the design of the study and write-up of the paper. CLT contributed to the design of the study and the write-up of the paper. SPS contributed to the design of the study and write-up of the paper. LV contributed to the design of the study, data analysis, write-up of the paper and general oversight of the study. SRH acts as garantor for the content of the paper.

Funding This project has received funding from the European Union's Horizon 2020 research and innovation programprogramme: MedEye under grant agreement No. 730731.

Disclaimer The funder had no input into the design of the contingent valuation survey, the collection of, analysis of, or interpretation of the data reported in the current study, and have not contributed to the writing of this manuscript.

Competing interests None declared.

Patient consent for publication Not applicable.

Ethics approval This study involves human participants and was approved by Newcastle University Ethics Committee Reference number 14156/2018. Participants gave informed consent to participate in the study before taking part.

Provenance and peer review Not commissioned; externally peer reviewed.

Data availability statement Data are available on reasonable request. Unidentifiable survey data are available from the authors on reasonable request.

Supplemental material This content has been supplied by the author(s). It has not been vetted by BMJ Publishing Group Limited (BMJ) and may not have been peer-reviewed. Any opinions or recommendations discussed are solely those of the author(s) and are not endorsed by BMJ. BMJ disclaims all liability and responsibility arising from any reliance placed on the content. Where the content includes any translated material, BMJ does not warrant the accuracy and reliability of the translations (including but not limited to local regulations, clinical guidelines, terminology, drug names and drug dosages), and is not responsible for any error and/or omissions arising from translation and adaptation or otherwise.

Open access This is an open access article distributed in accordance with the Creative Commons Attribution Non Commercial (CC BY-NC 4.0) license, which permits others to distribute, remix, adapt, build upon this work non-commercially, and license their derivative works on different terms, provided the original work is properly cited, appropriate credit is given, any changes made indicated, and the use is non-commercial. See: http://creativecommons.org/licenses/by-nc/4.0/.

ORCID iD

Sarah R Hill http://orcid.org/0000-0002-5408-2473

\section{REFERENCES}

1 Elliott RA, Camacho E, Jankovic D, et al. Economic analysis of the prevalence and clinical and economic burden of medication error in England. BMJ Qual Saf 2021;30:96-105.

2 Keers RN, Williams SD, Cooke J, et al. Prevalence and nature of medication administration errors in health care settings: a systematic review of direct observational evidence. Ann Pharmacother 2013;47:237-56.

3 Bates DW, Cullen DJ, Laird N, et al. Incidence of adverse drug events and potential adverse drug events. Implications for prevention. ade prevention Study Group. JAMA 1995;274:29-34.

4 Bates DW, Boyle DL, Vander Vliet MB, et al. Relationship between medication errors and adverse drug events. J Gen Intern Med 1995;10:199-205. 
5 Alqenae FA, Steinke D, Keers RN. Prevalence and nature of medication errors and medication-related harm following discharge from hospital to community settings: a systematic review. Drug Saf 2020;43:517-37.

6 Bates DW, Slight SP. Medication errors: what is their impact? Mayo Clin Proc 2014;89:1027-9.

7 Slight SP, Tolley CL, Bates DW, et al. Medication errors and adverse drug events in a UK Hospital during the optimisation of electronic prescriptions: a prospective observational study. Lancet Digit Health 2019;1:e403-12.

8 Jia P, Zhang L, Chen J, et al. The effects of clinical decision support systems on medication safety: an overview. PLoS One 2016;11:e0167683.

9 Thompson KM, Swanson KM, Cox DL, et al. Implementation of barcode medication administration to reduce patient harm. Mayo Clin Proc Innov Qual Outcomes 2018;2:342-51.

10 Hutton K, Ding Q, Wellman G. The effects of bar-coding technology on medication errors: a systematic literature review. J Patient Saf 2021;17:e192-206.

11 European Commission. CORDIS. Horizon 2020: Accelerated market launch of MedEye, a plug-and-play medication safety solution [web page], 2020. Available: https://cordis.europa.eu/project/id/730731 [Accessed 09 Oct 2021].

12 Steuten L, Buxton M. Economic evaluation of healthcare safety: which attributes of safety do healthcare professionals consider most important in resource allocation decisions? Qual Saf Health Care 2010;19:e6.

13 Segerson K. Valuing Environmental Goods and Services: An Economic Perspective. In: Champ PA, Boyle KJ, Brown TC, eds. A primer on Nonmarket valuation. Dordrecht. Springer Netherlands, 2017: 1-25.

14 Smith RD. Construction of the contingent valuation market in health care: a critical assessment. Health Econ 2003;12:609-28.

15 Boyle KJ. Contingent Valuation in Practice. In: Champ PA, Boyle KJ, Brown TC, eds. A primer on Nonmarket valuation. Dordrecht: Springer Netherlands, 2017: 83-131.

16 Carson RT. Contingent Valuation: A User's Guide. Environ Sci Technol 2000;34:1413-8.

17 Bouvy J, Weemers J, Schellekens H, et al. Willingness to pay for adverse drug event regulatory actions. Pharmacoeconomics 2011;29:963-75.

18 Lee GM, Salomon JA, LeBaron CW, et al. Health-state valuations for pertussis: methods for valuing short-term health states. Health Qual Life Outcomes 2005;3:17.

19 Kale A, Keohane CA, Maviglia S, et al. Adverse drug events caused by serious medication administration errors. BMJ Qual Saf 2012;21:933-8.

20 Morimoto T, Gandhi TK, Seger AC, et al. Adverse drug events and medication errors: detection and classification methods. Qual Saf Health Care 2004;13:306-14.
21 Aljadhey $\mathrm{H}$, Mahmoud MA, Mayet A, et al. Incidence of adverse drug events in an academic hospital: a prospective cohort study. Int $J$ Qual Health Care 2013;25:648-55.

22 Frew Eet al. Benefit assessment for cost-benefit analysis studies in health care using contingent valuation methods. In: Mclntosh $\mathrm{E}$, Clarke P, Frew E, eds. Applied methods of cost-benefit analysis in health care. Oxford: Oxford University Press, 2010.

23 Mitchell RC, Carson RT. Using surveys to value public goods: the contingent valuation method: Taylor \& Francis, 2013.

24 Shackley P, Dixon S. The random card sort method and respondent certainty in contingent valuation: an exploratory investigation of range bias. Health Econ 2014;23:1213-23.

25 Frey UJ, Pirscher F. Distinguishing protest responses in contingent valuation: a conceptualization of motivations and attitudes behind them. PLoS One 2019:14:e0209872.

26 Stata 15 [program]. 2017. ,.

27 Olsen JA, Donaldson C. Helicopters, hearts and hips: using willingness to pay to set priorities for public sector health care programmes. Soc Sci Med 1998;46:1-12.

28 Maddala GS. Limited-dependant and qualitative variables in econometrics. Cambridge: Cambridge University Press, 1983.

29 Sauzet O, Razum O, Widera T, et al. Two-Part models and Quantile regression for the analysis of survey data with a spike. The example of satisfaction with health care. Front Public Health 2019;7:146.

30 Belotti F, Deb P, Manning WG, et al. Twopm: two-part models. Stata J 2015;15:3-20.

31 Donaldson C. Eliciting patients' values by use of 'willingness to pay': letting the theory drive the method. Health Expect 2001;4:180-8.

32 Donaldson C, Birch S, Gafni A. The distribution problem in economic evaluation: income and the valuation of costs and consequences of health care programmes. Health Econ 2002;11:55-70.

33 Donaldson C. Valuing the benefits of publicly-provided health care: does 'ability to pay' preclude the use of 'willingness to pay'? Soc Sci Med 1999;49:551-63.

34 Mclntosh E, Clarke P, Frew E. Applied methods of cost-benefit analysis in health care: OUP Oxford, 2010.

35 Klose T. The contingent valuation method in health care. Health Policy 1999;47:97-123.

36 Arrow K, Solow R, Portney P. Report of the NOAA panel on contingent valuation: National oceanic and atmospheric administration, 1993.

37 Smith RD. It's not just what you do, it's the way that you do it: the effect of different payment card formats and survey administration on willingness to pay for health gain. Health Econ 2006;15:281-93.

38 Venkatachalam L. The contingent valuation method: a review. Environ Impact Assess Rev 2004;24:89-124.

39 Morrison MD, Blamey RK, Bennett JW. Minimising payment vehicle bias in contingent valuation studies. Environ Resour Econ 2000;16:407-22. 